Brit. J. industr. Med., 1963, 20, 226.

\title{
PNEUMOCONIOSIS IN CHINA-CLAY WORKERS
}

BY

\section{S. WARRAKI and Y. HERANT}

From Ain-Shams University Hospital and the Ministry of Public Health, U.A.R.

(RECEIVED FOR PUBLICATION OCTOBER 2, 1962)

A $70 \mathrm{~mm}$. radiographic survey in 914 workmen exposed to china-clay dust was made in 1959 in an industrial plant in which kaolin deposits are processed for the earthenware industry in Ayyat, United Arab Republic. All were ex-agricultural workers and thus not exposed to any industrial dust hazards.

The purpose of the survey was to study the prevalence of pneumoconiosis and active tuberculosis. Fifty subjects were considered to require further investigation and large films were therefore taken which showed the following results: five cases of pneumoconiosis; one case of pneumoconiosis and tuberculosis; and 13 cases of active tuberculosis. Of the five pneumoconiosis cases, two were classified as progressive massive fibrosis (P.M.F.), two as category 3 and one as category 1 simple pneumoconiosis. All had been heavily exposed for 15 years or more.

Case records of the pneumoconiosis group are given with follow-up observations for two and a half years. There were no important clinical or radiographic changes except that one of the two patients with P.M.F. died of cor pulmonale. Correlation of the clinical features and radiographic abnormalities was poor. The low prevalence of pneumoconiosis, in spite of the heavy and prolonged exposure, is emphasized. A sample of the airborne dust contained about $2 \%$ of $\mathrm{SiO}_{2}$.

China-clay or kaolin has long been suspected of causing pneumoconiosis. Middleton (1936) suggested that there might be a dust hazard in the china-clay industry. McNally and Trostler (1941) reported cases with densely mottled areas in the upper lobes of the lungs among workers in fuller's earth in Illinois. Similar cases have been reported by Bastenier (1950), and by Cavigneaux, Charles, Fuchs, and Tara (1950). Thomas (1952) described the findings of two necropsies; one on a worker in the ball clay industry, and one on a man who had been engaged in grinding china stone, a granite containing china-clay. Kaolinosis is the term given by Lynch and McIver (1954), who described the pathological studies in two cases of massive pulmonary fibrosis in kaolin workers in South Carolina. Six cases of pneumoconiosis in kaolin workers were described by Hale, Gough, King, and Nagelschmidt (1956) in Cornwall; two of these died and post-mortem examination showed large amounts of kaolin dust in the lungs.

This report describes six cases of pneumoconiosis discovered during the mass miniature radiographic survey of workers processing kaolin deposits for the earthenware industry in Ayyat, U.A.R. This group of workers was ideal for such a survey since the majority were ex-agricultural workers from the nearby land, and thus not engaged in dusty occupations before joining the plant.

The factory was built in 1880 by a private company. During the second world war the factory was extended with a considerable increase in the number of workers. No methods of dust suppression were used. Since 1961 the factory has become the property of the state, and new measures for dust control have been introduced. It is the only factory of its kind in the country for manufacturing chinaware and various refractory materials. Recently, ceramics have also been produced.

The china-clay is obtained by digging and is then brought to the factory where it is ground and sieved. The processes are all extremely dusty. The final ground dust is mixed with water to form the moulding clay. The method of washing away the wall of the pit with a high pressure stream of water, as in Cornwall, has not been adopted.

\section{Methods}

A mass miniature radiographic survey was carried out in September, 1959, on 914 men working in an 
industrial plant for processing china-clay deposits. A $70 \mathrm{~mm}$. "Odelca" mirror camera attachment with a four-valve mobile unit was used. The object of the survey was to ascertain the prevalence of pneumoconiosis and active tuberculosis.

The total population surveyed was 914 . There were no refusals. The periods of exposure at the time of the survey were as follows: less than 10 years, 264 workers; 10 to 15 years, $133 ; 15$ to 20 years, 326 (4 with pneumoconiosis); and more than 20 years, 191 workers (two with pneumoconiosis).

The films were read by three observers independently; differences were resolved by discussion and agreement between the readers in conference.

Large films $(12 \times 15$ in. $(30.48 \times 38.10 \mathrm{~cm})$.$) were$ taken when at least two of the three observers agreed that the cases were suspect. The 50 cases in which large films were made are categorized (I.L.O. Classification, 1950) in the Table.

\begin{tabular}{|c|c|c|c|}
\hline \multicolumn{4}{|c|}{ TABLE } \\
\hline \multirow{2}{*}{ Classified from M.M.R. } & \multirow{2}{*}{ No. } & \multicolumn{2}{|c|}{ Results from Large Films } \\
\hline & & Pneumoconiosis & $\begin{array}{c}\text { Active } \\
\text { Tuberculosis }\end{array}$ \\
\hline $\begin{array}{r}\text { Simple: Category } 1 \\
\text { Category } 2 \\
\text { Category } 3 \\
\text { Complicated }\end{array}$ & $\begin{array}{r}14 \\
11 \\
17 \\
8\end{array}$ & $\begin{array}{l}1 \\
1 \\
1 \\
3\end{array}$ & $\begin{array}{l}2 \\
2 \\
4 \\
5\end{array}$ \\
\hline
\end{tabular}

The 13 cases of active tuberculosis discovered did not include case 4 (below), which was regarded as a case of pneumoconiosis. In the pneumoconiosis cases, routine medical and industrial histories were taken, a clinical examination was carried out, and sputa were examined for tubercle bacilli. The E.S.R. was measured by the Westergren method. All cases were followed up until April, 1962, except one patient who died in 1960 .

\section{Case Reports}

Case 1.-M.M.A., aged 57, had worked in grinding for the last 17 years. He had previously been a farmer. He had no symptoms. On clinical examination only a few rhonchi were heard at both bases. The chest radiograph revealed increased bronchovascular markings with dispersed mottling, especially in the right mid-zone peripherally (category 1). Slight mottling was also noticed below the left clavicle. Sputum examination was negative for tubercle bacilli by direct methods and culture. The E.S.R. was $18 \mathrm{~mm}$. in the first hour. He continued with the same job and the last examination in 1962 revealed no marked change.

Case 2.-M.A.H., aged 50, worked in grinding and sieving for 15 years, before which he had worked on the land. He complained of mild dyspnoea on exertion and slight mucoid sputum for the last 11 months. Clinical

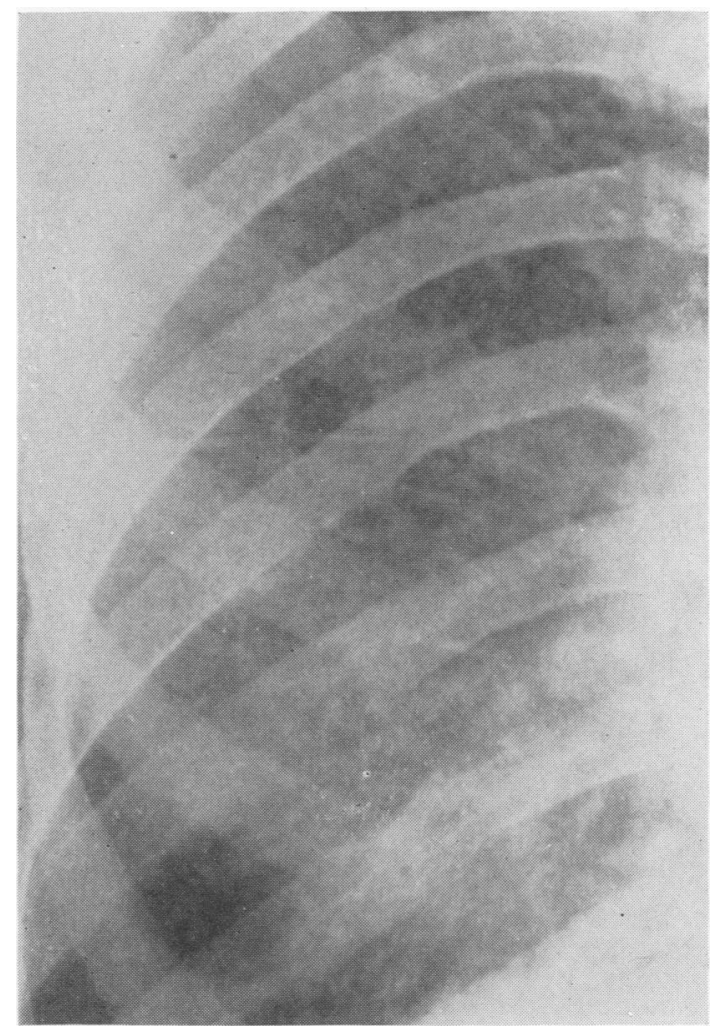

FIG. 1.-Case 2. Right upper zone showing simple pneumoconiosis (category 3 , mixed).

examination of the chest and cardiovascular and other systems was negative. A radiograph showed fine light mottling all over both lung fields (category 3, mixed) (Fig. 1). Sputum examination was twice negative for tubercle bacilli by direct smear only. The E.S.R. was $40 \mathrm{~mm}$. in one hour. He worked in the same processes and when last examined in 1962 no important clinical or radiographic change was reported.

Case 3.-S.A.B., aged 46, worked in loading of chinaclay, grinding, and sieving for 18 years. He had not previously been engaged in any dusty occupation. He had no complaints and clinical examination was within normal range. A chest radiograph (Fig. 2) showed bilateral diffuse nodular shadows with no accentuation of the bronchovascular markings (category 2, nodular). Sputum was negative for tubercle bacilli by repeated direct smears. The E.S.R. was $30 \mathrm{~mm}$. in the first hour. He continued to work in grinding until the last examination in 1962 when no change was reported.

Case 4.-A.E.A., aged 47, had worked at the mill for the last 16 years. Previously he had been an agricultural worker. During the last six months he had noticed that he had anorexia and was easily fatigued with mild dyspnoea on exertion. He also noticed that he had a cough 


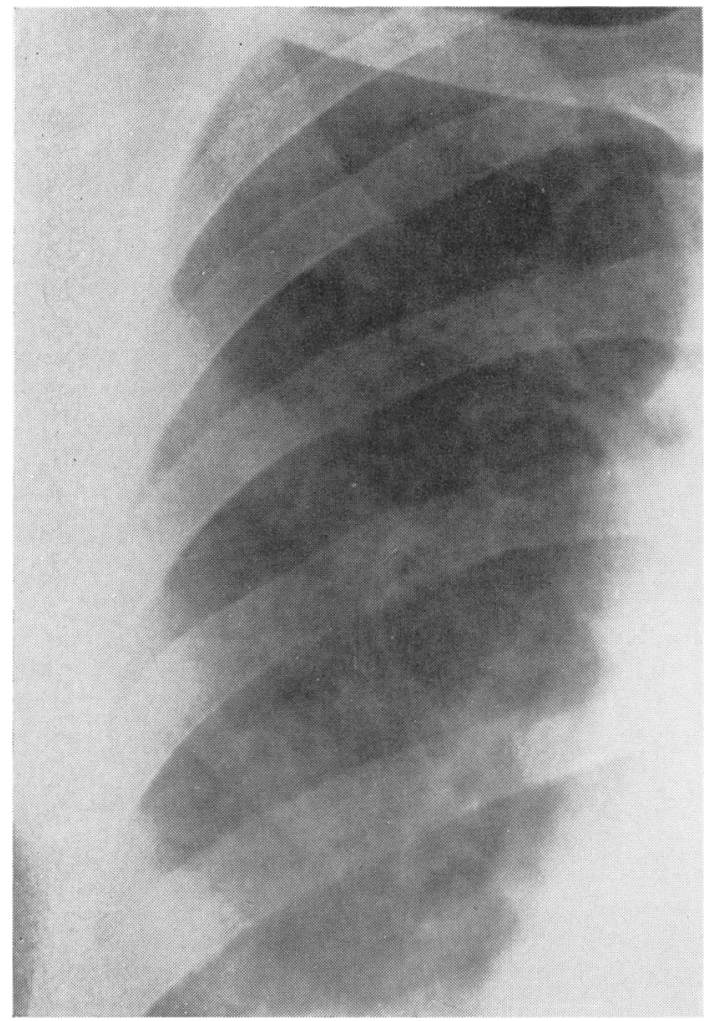

Fig. 2.-Case 3. Right upper zone showing simple pneumoconiosis (category 2, nodular).

with sputum which he did not have before. Frank blood was coughed up with sputum once. On examination his general condition was less than moderate and a few crepitations were heard over the interscapular region on the left side. A chest radiograph showed a rounded $5 \mathrm{~cm}$. cavity below the left clavicle; both the lung fields showed profuse mottling throughout, particularly in the midzones (category 2A, cavity). Sputum examination was positive for tubercle bacilli both by direct methods and on culture. The E.S.R. was $90 \mathrm{~mm}$. in the first hour. Streptomycin and isoniazid were given in hospital for nine months with great improvement in his general condition and radiographic appearance. The mild dyspnoea was however unaltered. He continued working in the plant as a door-keeper and the last examination in 1962 showed the same findings. The absence of any marked change in the nodulation in the film of the right lung after treatment for tuberculosis is the main reason for regarding this as a case of pneumoconiosis.

Case 5.-M.Y.M., aged 54, from the age of 29 worked in the factory in both grinding and sieving. He had had a chronic cough with a little mucoid sputum for the last three years, which was attributed to smoking. Bloodtinged sputum had occurred three times during the last year, and also moderate dyspnoea on exertion. Clinically,

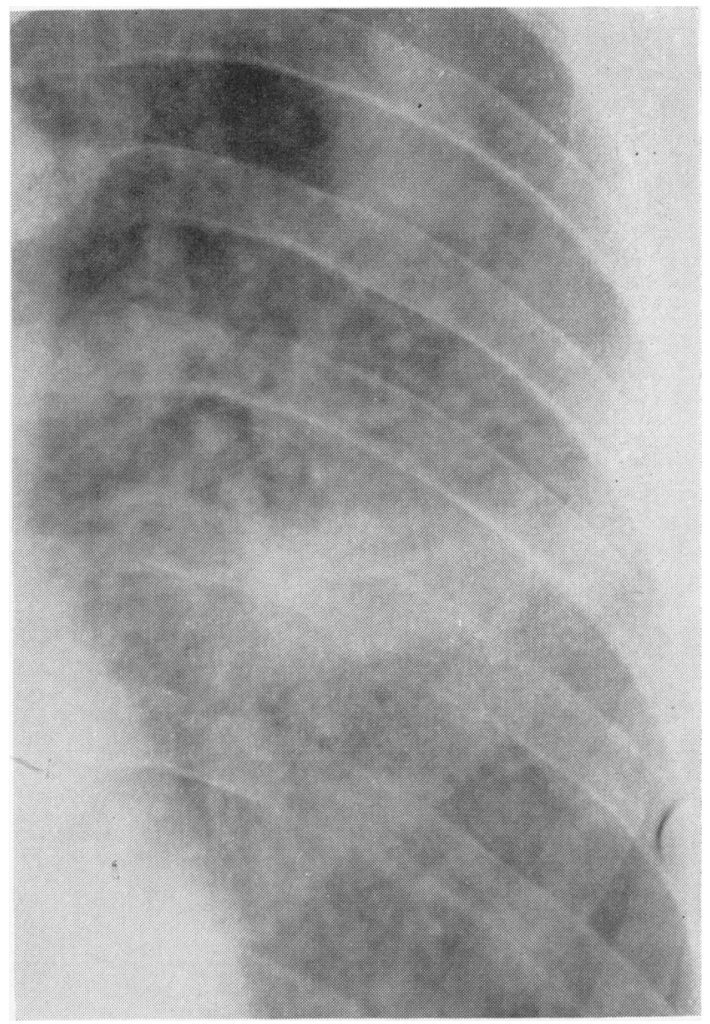

FIG. 3.-Case 5. Left upper zone showing areas of consolidation with surrounding nodulation (category $\mathbf{3 A}$ ).

fine rales were heard at both bases. Examination of the heart and other systems was normal. A chest radiograph showed homogeneous non-cavitated shadows in the left parahilar, left infraclavicular, and right apical zones. The rest of the lung fields showed a great deal of very fine mottling (category 3A) (Fig. 3). Sputum examinations for tubercle bacilli were negative by direct examination and on culture. The E.S.R. was $40 \mathrm{~mm}$. in the first hour. He continued with the same job and the last examination in 1962 showed no important change in his clinical or radiographic condition.

Case 6.-A.H.M., aged 57, had worked in grinding for the last 22 years. Before this he used to work on the land. He noticed dyspnoea on the least effort, was easily fatigued, and had bouts of lateral chest pain. He raised, on average, one coffee cupful of mucoid sputum daily which was never blood-tinged. Clinical examination showed that he had a temperature of $99^{\circ} \mathrm{F} .\left(37 \cdot 2^{\circ} \mathrm{C}\right.$. $)$, mild toxaemia, a tachycardia of 110 per minute, mild emphysema, and scattered rhonchi over the chest. The heart was clinically normal and the blood pressure was $140 / 95 \mathrm{~mm} . \mathrm{Hg}$. Moderate clubbing of the fingers was noticed. The chest film (Fig. 4) showed a huge dense mass, about $7 \mathrm{~cm}$. in diameter, in each hilum (category 2B). Both masses showed an irregular outline and evidence of 


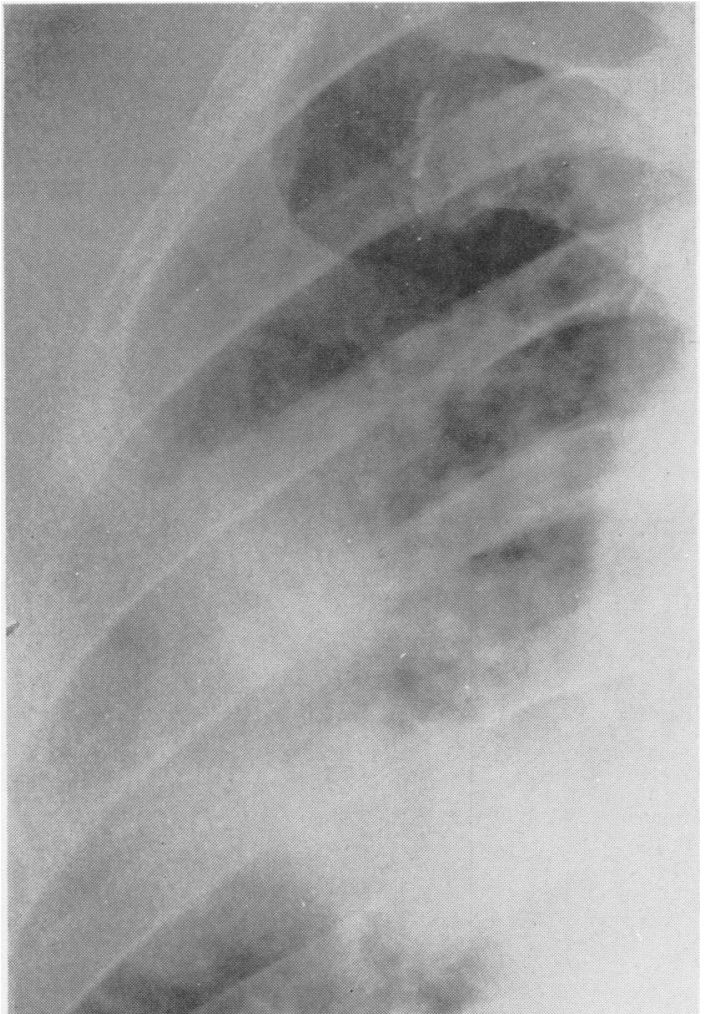

Fig. 4.-Case 6. Right mid and upper zone showing large area of consolidation (category 2B).

breakdown was noticed. The rest of the lung fields was irregularly and lightly mottled, with areas of focal emphysema. Sputum examination was repeatedly negative for tubercle bacilli by direct methods and on culture. The E.S.R. ranged between 70 and $110 \mathrm{~mm}$. in the first hour. He continued working in the same process for two months in spite of his disabling dyspnoea. From January, 1960 , he took to bed with marked weakness and wasting together with episodes of "bronchitis". He died on June 30,1960 , and a diagnosis of cor pulmonale was made. Permission for necropsy was not obtained.

\section{Discussion}

Industrial Hazards. - China-clay is prepared for large-scale use in the pottery industry as an important constituent of chinaware and also in the manufacture of refractory materials. Several processes are carried out in its production but the most dusty ones are grinding and sieving which were done in a closed chamber. Masks were available but were not used by the workers. Chemical analysis of dust samples collected at the mill showed that its chief constituent ( 83 to $86 \%$ ) was potassium aluminium silicate
$\left(\mathrm{K}_{4} \mathrm{Al}_{2} \mathrm{Si}_{2} \mathrm{O}_{9}\right)$; there was only 1 to $2 \%$ free silica. Microscopical examination of the same dust showed all particles were below 3.4 microns. The exposure time of the workers diagnosed as having pneumoconiosis varied from 15 to 25 years of 8 hours work daily. No quantitative samples of airborne dust were obtained. The factory was visibly very dusty.

Clinical Features.-While no complaint was obtained in two cases, the remaining four men had symptoms. These were mainly dyspnoea on exertion, cough, and slight mucoid sputum of no characteristic colour. In case 6, dyspnoea was marked, and one coffee-cupful of sputum was raised per day. This is a case of progressive massive fibrosis (P.M.F.) with probable cavitation. Repeated blood-tinged sputum occurred in case 5 (P.M.F.), while frank blood-spitting occurred once in case 4 (pneumoconiosis with tuberculosis). Clubbing of the fingers was only noticed in case 6 (P.M.F.).

Clinical examination was negative in cases 2,3 , and 5 , a few rhonchi on both sides were heard in case 1 , and crepitations were present in case 4 who had a tuberculous cavity. The raised E.S.R. in three cases can be partly explained by various degrees of anaemia due to endemic infections of the intestinal and urinary tracts by parasites (schistosomiasis, ancylostomiasis, and amoebiasis) since all the men were ex-landworkers. Sputum examinations were negative for tubercle bacilli in all cases except case 4 .

Radiographic Examination.-Hale et al. (1956), reporting on china-clay pneumoconiosis in Cornwall, mentioned that lesions were in the form of nodular mottling comparable in appearance to those of silicosis, or P.M.F. as seen in coal-miners' pneumoconiosis.

The radiographic patterns observed in the present series conform mostly with those reported by Hale. The mottling was not particularly dense, as described by McNally and Trostler (1941) in workmen exposed to fuller's earth; neither was there any elevation of hilar shadows or strand-like opacities, as described by Géher (1955) and by Barth, Frik, and Scheidemandel (1956) in pneumoconiosis due to aluminium dust. Case 4, whose condition was complicated by tuberculosis, had a nodular type of lesion. The appearance and location of the confluent opacities in cases 5 and 6 were comparable to those of P.M.F. in coal-miners. In these two cases cavitation was not confirmed, though in case 6 there was a suspicion of cavitation on account of the breakdown shown by the postero-anterior radiograph as well as the quantity of sputum. Kilpatrick, Heppleston and Fletcher (1954) reported that cavitation may not be detected in P.M.F. because of the remarkable way in 
which these cavities may refill completely. A radiograph should thus be taken shortly after the patient has expectorated a large quantity of sputum; also a lateral projection and a tomogram should be done. Moreover, even if cavitation is demonstrated, this cannot be considered tuberculous unless confirmed by bacteriological examination. In our two cases of P.M.F. cavitation was not confirmed, nor were sputum examinations positive for tubercle bacilli.

Except for case 6 (P.M.F.), correlation of clinical and radiographic features was poor. This again compares with the slight correlation reported in coal-miners' pneumoconiosis by Higgins and Cochrane (1961).

Diagnosis.-Though no histological evidence was available, yet the diagnosis of pneumoconiosis was made on account of the typical radiographic appearances and the long exposure to a very dusty atmosphere. The men were agricultural workers who had not previously worked in a dusty occupation. The composition of the dust was almost pure kaolin, and the free silica content was too low to produce silicosis. Follow-up examinations over two and a half years have shown no progression in the radiographic appearances; this was considered sufficient to exclude any infective cause for the radiological abnormalities. In the two cases with P.M.F., the massive shadows were typical in appearance and distribution, so that the possibility of neoplasm was not considered. This was further substantiated by the subsequent course of these two cases.

We wish to acknowledge our indebtedness to Dr. O. Rifaat, Faculty of Agriculture, Cairo University, for his assistance in particle measurement and the chemical analysis of the dust.

\section{REFERENCES}

Barth, G., Frik, W., and Scheidemandel, H. (1956). Dtsch. med.Wschr., 81, 1115 .

Bastenier, H. (1950). Arch. belges Méd. soc., 8, 81.

Cavigneaux, A., Charles, A., Fuchs, S., and Tara, S. (1950). Arch. Mal. prof, 11, 34.

Géher, F. (1955). Fortschr. Röntgenstr., 82, 598.

Hale, L. W., Gough, J., King, E. J., and Nagelschmidt, G. (1956). Brit. J. industr. Med., 13, 251.

Higgins, I. T. T., Cochrane, A. L. (1961). Ibid., 18, 93

Kilpatrick, G. S., Heppleston, A. G., and Fletcher, C. M. (1954). Thorax, 9, 260.

Lynch, K. M., and McIver, F. A. (1954). Amer. J. Path., 30, 1117.

McNally, W. D., and Trostler, I. S. (1941). J. industr. Hyg., 23, 118. Middleton, E. L. (1936). Lancet, 2, 59.

Thomas, R. W. (1952). Ibid., 1, 133. 